\title{
Resistência nômade: arte, colaboração e novas formas de ativismo na Rede
}

\author{
Fernando do Nascimento Gonçalves ${ }^{1}$ \\ Universidade do Estado do Rio de Janeiro \\ azert46@yahoo.com
}

\begin{abstract}
Resumo: O presente trabalho pretende discutir os usos das tecnologias digitais de comunicação nas novas formas de mobilização social através da arte. A questão central a ser abordada é um fenômeno surgido nos anos 90 , da apropriação, por parte de artistas, cidadãos comuns e ativistas de recursos das redes digitais combinados com recursos presenciais para mobilizar, sensibilizar e amplificar ações coletivas e engajar um grande número de pessoais em torno de causas sociais. Tais ações indicam um outro fenômeno, que é o da redefinição dos conceitos de arte e política, tornando-os sensivelmente diversos dos das vanguardas européias do começo do século $X X$ e do alto-modernismo dos anos 6o. Tal mudança parece estar abrindo, por isso mesmo, espaço para o redimensionamento das práticas de resistência cultural na atualidade.
\end{abstract}

Palavras-chave: Comunicação; Arte; Tecnologia; Mídia Tática; Ativismo.

\begin{abstract}
This article discusses the uses of communication digital technology in new forms of social mobilization by artists. The main point to be presented is a phenomenon started in the beginning of the 9o's: the artistic and activist appropriation of communication online networks combined to old media and to other presential resources in order to touch and to amplify political actions and to engage collectively a great amount of people in aid of social issues. Such actions indicate at the same time the redefinition of the concepts of art and of politics - making them quite different from the ones of the early europeen avant-gards and of high modernism of the 6o's - and the practices of political resistance in contemporary culture.
\end{abstract}

Key-words: Communication; Art; Technology; Tactical Media; Activism.

\footnotetext{
${ }^{1}$ Doutor em Comunicação e Cultura pela UFRJ, professor da Faculdade de Comunicação da Uerj e pesquisador em Comunicação, Arte e Tecnologia no grupo de pesquisa CAC

(Comunicação, Arte e Cidade), vinculado ao Programa de Mestrado em Comunicação da Uerj, na linha Novas Tecnologias e Cultura. Foi pesquisador visitante na Tisch School of the Arts da Universidade de Nova York, em 2002, com recursos do Conselho Nacional de Desenvolvimento Científico e Tecnológico (CNPq).
} 
Resumé: Cet article a comme but discuter l'emergence de nouvelles formes de mobilization sociale a travers l'utilisation des technologies numériques. Le point central a être presenté est le phenomène surgit aux années 90 de l'appropriation des réseaux virtuels combines a d'autres resources présentiels par des artistes et des activistes pour mobiliser, toucher et amplifier l'effect des actions politiques et pour engager un grand numéro de personnes autour des causes sociales. Ce genre d'action indique un changement au niveau des concepts d'art et de politique - qui les rend assez différents des conceptions chers aux avant-gardes du début du XX siècle et du haut-modernismo des annés 6o. En même temps, ce changement semble indiquer aussi un remodèlemement des practiques de résistance politique dans la culture contemporaine.

Mots-clef: Communication; Art; Technology; Média Tactiques; Activismo.

Resúmen: Este artículo discute los usos de la tecnologia digital de comunicación em las nuevas formas de mobilización social a traves del arte. La questión central a ser presentada es un fenômeno surgido em los años 9o: la apropriación, por artistas y activistas, de las redes digitales combinadas con recursos presenciales para mobilizar, sensibilizar y enganchar gran numero de personas al redor de causas sociales. Estas acciones indican um outro tipo de fenômeno: la redefinición de los conceptos de arte y de política, sensiblemente distintos de los conceptos de las vanguardias europeas y del alto-modernismo de los años 6o. Este cambio parece abrir, por esa razón, espacio para el remodelamiento de las practicas de resistência política en la actualidad.

Palabras-clave: Comunicación; Arte; Tecnología; Medios Tacticos; Activismo.

\section{Introdução}

O presente artigo tem como objetivo discutir a emergência de práticas artísticas que se apóiam no uso crítico de tecnologias de informação e comunicação para produzir resistência a discursos e práticas de poder, através de ações virtuais e em espaços públicos. Tais práticas apontam para novas formas de atuação social, sensivelmente distintas daquelas utilizadas nos anos 60 e 70, na contracultura. 
Nessas ações, são as próprias noções de política, ativismo e arte que parecem ser redesenhadas. Tais redefinições permitem não apenas flagrar o surgimento de novas formas de produzir resistência, como podem talvez munir-nos com recursos para enfrentar os dilemas resultantes das mudanças que vem ocorrendo na sociedade. Partimos da premissa de que os processos comunicativos contêm um aspecto de alteridade para além daqueles presentes nos conhecidos modelos de reconhecimento midiático dos apelos da publicidade, na informação jornalística ou nos discursos mercadológicos e institucionais de relações públicas. Nesse aspecto de alteridade, o ato comunicativo não estaria apenas subordinado "às marcas reconhecíveis dos códigos nem às repercussões identitárias dos sujeitos”, como afirma Janice Caiafa (2005), mas à capacidade de problematizar esses códigos e criar novas referências subjetivas.

O fenômeno que trazemos à discusssão representa precisamente a possibilidade de explorar esses aspectos de alteridade no campo da comunicação, pois parece constituir ações afirmativas e de oposição às novas configurações do capitalismo que, organizado em rede, gera formas de controle e poder dificilmente apreensíveis por serem cada vez mais fluidas.

A principal hipótese do artigo é que as ações realizadas por "artistasativistas”, através das tecnologias digitais acionadas criativamente com outras mídias, parecem formar uma combinação capaz de evocar esse aspecto de alteridade que queremos realçar nos processos comunicativos na atualidade.

\section{Rede, híbridos e o redimensionamento das noções de arte e política}

O momento atual vem se caracterizando pelo fim das formas de representação do mundo fundadas em unidades coerentes e ordenadas. A crise desses modelos de representação parece ter como indício a presença daquilo que Bruno Latour (1994, p.54) chamou de "híbridos", a figura virulenta da multiplicidade que não cabe em categorias e que na modernidade era "varrida para baixo do tapete" por meio de operações de purificação. 
Para Latour, os híbridos emergem como intermediários entre elementos heterogêneos - objetivos e subjetivos, individuais e coletivos. São formas que "se conectam ao mesmo tempo à natureza das coisas e ao contexto social, sem, contudo, reduzir-se nem a uma coisa nem a outra" (Latour, 1994, p.11). Essa intermediação é possível, segundo o autor, pois tais elementos não são estanques. Esse pensamento é corroborado por René Berger, para quem a certeza em nossas categorias se enfraqueceu na atualidade justamente pela percepção de que tudo é, de certa forma, transversal, ou seja, nada ou nenhum ser existe isoladamente (Berger in: Domingues, 2003, p. 43). Este é o cerne do pensamento sobre as redes, que Pierre Musso define como sendo "uma estrutura de interconexão instável composta de elementos em interação e cuja variabilidade obedece a alguma regra de funcionamento" (in: Parente, 2004, p. 31).

Como afirma Berger (ibidem), os laços ou elos que formam essas estruturas sempre existiram ("laços endógenos que ligam os componentes de um organismo, laços exógenos que ligam os seres entre si e com seu meio ambiente”), bem como seus produtos, os híbridos. Contudo, agora teriam se tornado mais visíveis graças aos meios técnicos que, ao operarem eles próprios por conexões, nos permitem fazer articulações de toda ordem, tornando-as perceptíveis. As redes informáticas e as redes virtuais de comunicação constituem talvez a faceta mais visível desse sistema mais amplo das redes, pois dão a ver claramente as estruturas de interconexão entre elementos em interação de que nos falou Musso e que podem ser flagradas em distintos âmbitos.

É assim que, na sociedade atual, o múltiplo vaza e prolifera, evidenciando que na trama do social somos e sempre fomos híbridos, constituídos nos interstícios de complexas redes (científicas, biológicas, institucionais, culturais, econômicas, políticas, midiáticas, afetivas etc). André Parente (2004, p.92) nos faz lembrar que vivemos numa época em que as tecnologias de informação e da comunicação passaram a ter um papel crucial na nova ordem mundial e que as redes seriam, a um só tempo, uma espécie de "paradigma e de personagem principal das mudanças em curso". Parente acredita que nossa época é caracterizada por operações de articulação e combinação, de edição e montagem, onde nosso pensamento e discurso não exprimiriam a essência das coisas, mas "colagens que apenas indicam os padrões das 
redes que nossas articulações tecem” (Parente, 2004, p. 95). São os híbridos e as redes que nos permitem retomar as noções do político e do artístico e revisitá-las.

Curiosamente, chama a atenção no trabalho de muitos artistas na atualidade o que parece ser uma diluição das fronteiras entre arte e política, entre política e criação, entre arte e vida, fusões que já vinham sendo gestadas desde as vanguardas do começo do século XX e encontram hoje condições mais propícias para sua efetivação. A atualidade, por caracterizar-se exatamente pelo esgarçamento das fronteiras e pela proliferação dos híbridos, dá lugar a produções, onde arte e política são indissociáveis, embora de forma distinta de períodos anteriores.

A arte, por exemplo, nos movimentos das vanguardas européias do início do século XX e dos anos da contracultura foi marcada por experiências liminais, de conjuração de limites e era radicalmente engajada contra as instituições e o mercado da arte. Contudo, partir do final dos anos 70, abre-se a variados tipos de mediação, tendo como bases a apropriação, o trabalho colaborativo interdisciplinar e o uso de referências do cotidiano, inclusive da cultura de massa e da tecnologia ${ }^{2}$. A obra de arte contemporânea liberta-se assim da necessidade de "ter que dizer alguma coisa". Antes, indica e discute questões e tampouco é necessariamente caracterizada por uma concretude objetual: desmaterializa-se e recompõe sob novas formas - formasimagem, formas-processo, formas-performance -, todas quase sempre combinações de distintas referências que são recortadas e acionadas pelo artista e pelo público, construindo sentidos nunca estáveis.

Na perspectiva das redes, que estamos adotando, poderíamos afirmar que, da mesma forma que a arte contemporânea não diz respeito apenas ao cânone e ao estético, mas também ao político, ao urbano, ao sensual, ao banal, o político não dialoga apenas com o ideológico, mas também com o cultural, o subjetivo e o artístico.

Este mudança de sensibilidade e do de encarar os elementos constitutivos da experiência social permitiu o surgimento de novas estratégias nos campos da arte e

\footnotetext{
${ }^{2}$ A esse respeito, remeto ao estudo que realizei sobre o trabalho da artista americana Laurie Anderson, que buscou exatamente discutir os usos singulares da tecnologia feita pela artista, publicado em 2006, "Fabulações Eletrônicas: poéticas da comunicação e da tecnologia em Laurie Anderson”.
} 
dos ativismos políticos. Ao analisar os chamados movimentos sociais do século XXI, por exemplo, Maria Glória Gohn (2003) afirma que estes seriam menos reinvindicativos e libertários e mais operativos e propositivos; não recusariam o diálogo com o poder, antes negociariam com ele ou o subverteriam; não lutariam por bandeiras isoladas, mas por causas universais que integram vários atores sociais, fortalecendo lutas locais; não se comunicariam ou organizariam "clandestinamente", mas em redes eletrônicas, para realizar protestos e manifestações não-violentas no ciberespaço e nos espaços urbanos.

\section{Usos táticos e artísticos de mídia e as novas formas de ativismo na Rede}

Por abandonarem muitas de suas históricas referências, a arte e a política parecem hoje reivindicar outras referências para expressar-se e produzir diferença. Por um lado, o político seria construído não mais apenas a partir de uma recusa ou de uma oposição sistemáticas, mas também de uma negociação que aceita o conflito como condição mesma da realização de um embate e de uma oposição. Por sua vez, a arte, ao fundir-se com a vida, irá muitas vezes abrir mão do significado e da interpretação da obra para assumi-la enquanto processo de articulação de signos que se presta a outras modalidades de fruição e a uma comunicação de outra ordem.

A este respeito, Ricardo Rosas (2003) afirma que a fusão entre arte e vida "não nulifica o estético", antes o fortalece e reinventa. Exatamente porque nessa fusão o que morre é a tradicional noção da genialidade do artista para dar-se lugar a um processo criativo onde o artista seria um "pensador, um criador de estratégias de ação, um arquiteto de atos que vão reverberar”. Nesse sentido, o artista perde o "monopólio" da criação no contexto dessas obras/ações que seriam a só tempo, arte e pensamento, táticas conceituais. É neste sentido que vemos o surgimento das práticas artísticas apoiadas nas tecnologias de informação e comunicação, usadas para produzir novas formas de resistência cultural e um tipo de ativismo organizado através da comunicação em rede.

Torna-se assim compreensível o aparecimento da noção de "artista-ativista", termo criado pelo grupo americano Critical Art Ensemble (1994, p. 26) para definir aqueles que, sendo ou não reconhecidamente artistas, se apropriam das mídias e 
tecnologias para produzir novas formas de intervenção cultural que seriam “artísticas” em seus modos de desenvolvimento e operacionalização.

Na mesma linha de pensamento, o teórico de mídia e de internet Geert Lovnik (2005) acredita que, no contexto do uso das novas mídias, há pouca diferença entre artistas e ativistas, pois ambos "exploram as mídias e não se limitam a usar programas e estéticas padronizados”. Ao abordar as novas relações entre arte, política e internet, quando esteve em São Paulo, em agosto de 2005, Lovnik afirmou que o traço comum entre eles é a "fome de pesquisa e sua mentalidade de questionamento à autoridade". Acredita ainda que outra marca desses movimentos de arte ativista contemporâneos seria o trabalho colaborativo3, que ajudaria também a apagar a noção do "gênio individual" do artista. O colaboracionismo dilui o peso da "autoria" em equipes multimídia, interdisciplinares, onde o artista pode trabalhar com engenheiros de sistemas, programadores, designers, vídeo-makers, entre outros, ou em parceria com outros artistas. Seja em equipes multidisciplinares ou em coletivos de artistas, cada um atua com competências distintas somando esforços em prol de uma ação ou de um trabalho de arte.

Crucial para estes "artistas-ativistas" parece ser então a possibilidade de combinar e usar taticamente esses recursos para atingir determinados objetivos artísticos e políticos. Essa modalidade de uso de mídias e tecnologias de comunicação levou ao surgimento do termo "mídia tática", criado pelo artista polonês Krzystof Wodzisko, derivado dos estudos de Michel de Certeau, e então desenvolvido por Lovnik e David Garcia (2003).

Ao abordar a cultura popular e as relações de consumo, Certeau (1994, p. 45) fala-nos da possibilidade de uma "politização das práticas cotidianas", através do deslocamento da ênfase na observação das representações sociais para os usos que podem ser feitos dessas representações, através de uma "estética da apropriação". Essas operações permitiriam realizar subversões em determinadas lógicas culturais e

\footnotetext{
$3 \mathrm{O}$ trabalho colaborativo no campo da arte não é novo. Tanto na forma dos chamados “coletivos" de artistas ou associações, pelo menos desde o início das vanguardas européias se tem notícia de organizações desse tipo, conforme explica Ricardo Rosas (2003c). Hoje, porém, essas associações e parcerias ficam mais evidentes pelo tipo de ação desenvolvida, especialmente no âmbito de uma arte que se baseia em tecnologia.
} 
promover dissonâncias.. É nesse contexto que o autor vai diferenciar os termos "tática" e "estratégia".

Para Certeau, "tática" implicaria sempre um arranjo multiforme e "subreptício" de elementos do cotidiano, sem objetivos duráveis ou necessariamente predeterminados. A tática implica uma noção de cálculo - mas sempre precário e temporário, que caracterizaria uma "criatividade dispersa e bricoladeira", feita de ocasião. Já “estratégia” implicaria operações de cálculo de relações de força, de planejamento e da gestão dessas relações a partir do isolamento e manipulação dos elementos que compõem a lógica da representação. A nacionalidade política, econômica ou científica seria, segundo o autor, um exemplo desse modelo estratégico (Certeau, 1994, p. 46).

O conceito de "mídia tática" firmou-se, segundo Ricardo Rosas (2003), nos anos 90, fruto de práticas de ativistas de mídia e festivais de novas mídias na Europa e nos EUA. Seu fundamento básico são as produções do tipo "faça-você-mesmo", realizando um uso diferenciado das potencialidades de comunicação dos diversos meios. Isso não quer dizer que a mídia tática seja uma mídia "alternativa", pois seu conceito foi criado justamente para fugir da idéia de recusa a dicotomias do tipo "amador x profissional", "alternativo x mainstream”. A idéia de mídia tática baseia-se precisamente na flexibilidade de certos usos, assim como no trabalho colaborativo e na mobilidade entre as diferentes mídias, dentro do contexto cultural-midiático existente, para combatê-lo de "dentro". Por isso, o mais importante, como afirma Rosas, são as conexões temporárias que conseguem ser feitas através desses usos táticos das mídias.

Para Lovnik e Garcia, foi o gradual barateamento dos novos e antigos meios que possibilitou o surgimento das mídias táticas, que consistem em nada mais que o uso e a apropriação de mídias diversas usadas para promover "inversões temporárias no fluxo do poder" (Garcia e Lovnik, 2003).

Porém, mídias táticas não consistem apenas em recursos mais sofisticados. Podem ser também os recursos da comunicação oral e elementos presentes no cotidiano e nos espaços públicos, onde se dá a mistura do popular, do erudito e do massivo, como afirma Canclini. Daí também sua vasta abrangência, que vai da 
reutilização de mídias como televisão, rádio, vídeo, meio impresso e artes em geral, a websites, produção de softwares e todo tipo de mídia eletrônica, incluindo igualmente, se for o caso, a combinação desses elementos com performance, djs, teatro de rua, ocupações de prédios públicos ou abandonados, panfletagem, adesivos, dentre outros meios que estiverem "à mão".

Como Lovnik e Garcia, Ricardo Rosas e Tatiana Wells consideram esses usos táticos de mídia e tecnologias como uma nova forma de ativismo, que começou a surgir a partir dos anos 80. Para Rosas e Wells (2003), esses movimentos visariam oferecer uma outra maneira de pensar "a função transgressiva da comunicação", através de um discurso estético. Essas características seriam oriundas, segundo os autores, tanto dos movimentos de contracultura dos anos 60 quanto das vanguardas européias, que preconizavam a fusão entre arte e vida e a desinstitucionalização da arte.

Se considerarmos "ativismo" uma doutrina ou forma organizada de argumentação que privilegie a prática de transformação da realidade em detrimento da atividade exclusivamente especulativa e como iniciativas que buscam soluções para os desafios da vida coletiva, então, segundo a visão de Rosas e Lovnik, estaríamos, de fato, diante de novas formas de ativismo.

A hipótese parece ser corroborada pelas análises de Maria da Glória Gohn sobre os movimentos sociais na atualidade. Para Gohn, esses movimentos seriam caracterizados menos pela transgressão e pelo radicalismo e mais por um aspecto reivindicativo e propositivo e constituiriam "novas formas de associativismo"(Gohn, 2003, p. 18).

Organizados em redes, os movimentos sociais surgidos a partir dos anos 90 se caracterizariam muitas vezes por mobilizações pontuais, por demandas específicas e não por processos de mobilização em massa. Essas novas formas de associativismo atuariam por meio de redes sociais locais, regionais, nacionais e internacionais (formadas por distintos atores sociais) e utilizam-se dos novos meios de comunicação e informação como a internet para articular e mobilizar cidadãos, sem, contudo, exigir deles militância constante. (ibid, p,13). 
As redes sociais seriam estruturas próprias da sociedade contemporânea globalizada e informatizada. Decorrem da busca de formas de articulação entre o local e o global, como afirma Scherer-Warren:

"trata-se de buscar os significados dos movimentos sociais num mundo que se apresenta cada vez mais interdependente, intercomunicativo, no qual surge um úmero cada vez maior de movimentos de caráter transnacional, como os dos direitos humanos, pela paz, ecologistas, étnicos e outros”. (1996, p. 10)

É o caso de movimentos que lutam por causas cada vez mais globais com efeitos e ações locais, como os movimentos anti-globalização, e por causas nacionais ou locais, como o movimento brasileiro dos sem-terra (nacional) e dos sem-teto que lutam por reformas urbanas (regional, em São Paulo).

Curiosamente - e essa é mais uma das características dessas novas formas de ativismo -, esses e outros movimentos, por atuarem em rede, contam por isso com a solidariedade de outros movimentos, que eventualmente podem se unir às lutas uns dos outros para aumentar o poder de pressão, realizar protestos e fazer manifestações conjuntamente, como foi o caso de Seattle, em 1999 (movimento anti-globalização), e de Chiapas, México, em 2001 (movimento Zapatista). Atualmente, muitos grupos, formados por programadores de software e ativistas sociais, especializam-se na luta por causas políticas online e por isso foram denominados "hacktivistas"4.

Segundo Rosas (2003c), embora se possa reportar ações isoladas em anos anteriores, 1998 teria sido o ano-chave para a consolidação do hacktivismo. Foi neste ano que o hacker inglês "JF" invadiu mais de 300 sites colocando textos e imagens com mensagens anti-nucleares. Foi igualmente em 1998 que surgiu o primeiro site dedicado ao tema, pelo grupo de hackers do Cult of the Dead Cow, a cujo membro "Oxblood Ruffin" é atribuída a criação do termo "hacktivismo". Ao longo de todo aquele ano, foram reportadas diversas ações hacktivistas em sites da Austrália, Índia, China e países de quase todos os continentes.

\footnotetext{
4 Segundo Ricardo Rosas, movimento e grupos que realizam "ação direta no ciberespaço". Geralmente, invasões de sites para inserir mensagens e imagens de protesto, simulação de sites oficiais com conteúdo alterado e práticas de desobediência civil eletrônica como os sitins virtuais - prática adaptada do ativismo de rua para as redes que busca bloquear temporariamente e sem danos permanentes o acesso a sites de governos e empresas, como forma de protesto (Rosas, Ricardo. Hacktivismo: ação direta nas auto-estradas da informação. In: Rizoma.net, 2003).
} 
Desde então o movimento cresceu significativamente. Seja para protestar contra a situação na Palestina, contra a Organização Mundial de Comércio (OMC) ou a CNN, a dominação das grandes corporações, pornografia infantil, transgênicos ou a censura em países como a China, o campo de ação dos hacktivistas é bastante vasto. O que não impede, igualmente, as controvérsias entre os diferentes grupos em ação (para alguns, por exemplo, congestionar o acesso a sites é violar a livre expressão). As táticas podem ser várias, da pura invasão no estilo do hacketivismo tradicional ou a blocagem de acessos a sites e programas de mensagens escondidas em imagens para fugir da censura (tipo o "Camera/Shy", criado pelo Cult of the Dead Cow), até pichação com mensagens anti-guerra em games online, como exemplifica Ricardo Rosas(2003).

\section{Arte, ativismo e a resistência "nômade"}

É no começo dos anos 90 que começamos a assistir ao surgimento de um outro fenômeno, o da convergência das ações hacktivistas com a de artistas. Alguns grupos passaram a se especializar em ações para as quais reivindicavam um cunho artístico-ativista para realizar ou apoiar protestos, usando as redes virtuais, mídias diversas e ações de intervenção em espaços públicos, separada ou combinadamente.

A mistura entre arte e "ciberativismo", que tem cada vez mais se popularizado entre artistas eletrônicos, programadores de software e hackers, atualiza as questões postas por grupos como os dadaístas e situacionistas5, polemizando sobre questões políticas, direito autoral (anti-copyright) e interatividade. Esses grupos - chamados coletivos - são constituídos por ativistas, intelectuais, estudantes, artistas e pessoas comuns que começaram a se mobilizar e a usar taticamente antigos e novos meios para difundir e compartilhar ações, experiências e obras artísticas que constituem - claramente ou não - formas de resistência temporárias e nômades, apoiadas em redes de comunicação.

Segundo Rosas, esses grupos trabalhariam diretamente na confluência de ativismo, net arte e programação de software, como é o caso dos grupos americanos

\footnotetext{
5 Importante movimento internacional ativista muito ativo nos anos 6o, que contou como um dos principais mentores Guy Debord.
} 
Eletronic Disturbance Theater (EDT) e Critical Art Ensemble (CAE) e do suíço Etoy, que organizam ações online, um misto de performance, jogos eletrônicos e hacktivismo

Um exemplo que ficou muito conhecido foi a ação performática do EDT, em 1998, para auxiliar a situação dos zapatistas ${ }^{6}$ de Chiapas, México, no episódio do massacre de comunidades indígenas que mobilizou a opinião pública mundial em 1996. Realizando diversas ações de "desobediência civil eletrônica"7 contra o governo mexicano, o EDT criou o programa FloodNet, que permite repetidos downloads num site por várias pessoas no mundo inteiro, congestionando seu acesso, constituindo uma verdadeira performance coletiva.

Outro caso que ilustra bem o que ficou conhecido como ação de desobediência eletrônica é o caso Etoy (Etoy in: Tribe and Jana, 2006, p. 40-42). Em 1995, um grupo de artistas conceituais criou um website no endereço www.etoy.com. Em outubro de 1997, o www.etoys.com, uma loja americana de brinquedos online, abriu seus negócios - dois anos após a etoy.com ter registrado seu domínio e começado a colocar seu conteúdo no site. Em 1999, a www.etoys.com tornou-se público e um dos sites mais valiosos da internet, avaliado em 6 bilhões de dólares. Eles também comunicaram a www.etoy.com e reclamaram que a semelhança dos domínios estava confundindo os clientes e comprometendo a marca. Mais tarde, solicitaram aos clientes que haviam acessado o site dos artistas por engano que reclamassem da linguagem gráfica e das imagens lá. A essa altura, a www.etoys.com ofereceu comprar e nome "etoy", mas seus proprietários se recusaram a vender.

Assim, em setembro de 1999, a www. etoys.com moveu um processo contra a www.etoy.com. O argumento era de que a www.etoy.com deveria desaparecer por haver um domínio similar, apesar do fato de ele ter sido registrado dois anos antes que a www.etoys. com. Uma corte da Califórnia sentenciou os operadores da

\footnotetext{
${ }^{6}$ Exército civil que, ao ampliar sua causa - inicialmente anti-NAFTA - uniu-se a outros atores sociais, tornando-se um movimento anti-globalização organizado em uma complexa rede virtual mundial, com ações ativistas online e presenciais, como explica Henrique Antoun (in: Parente, 2004, p. 229).

7 Segundo o Critical Art Ensemble, "atividade não-violenta de confrontação não-física entre forças opostas", que buscam ocupar taticamente espaços-chave que permitam pressionar instituições reconhecidas envolvidas em ações anti-éticas ou criminais (CAE, 1996, p. 18)
} 
www.etoy.com a pagarem uma multa de 10 mil dólares a cada dia que o website continuasse a operar com esse domínio.

Muitas pessoas da comunidade online ficaram ultrajadas pelo fato do dinheiro e dos negócios importarem mais do que os direitos na internet. A comunidade organizou (entre outros protestos) o que foi efetivamente um protesto digital. Eles lançaram um programa que, uma vez iniciado, fazia com que o computador acessasse repetidamente o site da www.etoys.com. Eles então encorajaram os que estavam a favor da www.etoy.com que baixassem o programa e o rodassem uma semana antes do Natal. Essencialmente, esse programa permitia que os usuários participassem de um "protesto virtual” não-violento, pois o ataque não danificava o site da www.etoys.com, ele simplesmente impedia as pessoas de acessálo enquanto continuasse o protesto. Se muitos manifestantes tentassem acessar a página, os clientes não poderiam acessar a página ao mesmo tempo e não poderiam fazer suas compras de Natal na www.etoys.com. Com alguns dias de protesto virtual, as ações da www.etoys.com começaram a cair. A www.etoys.com apresentou então uma ordem judicial contra um dos sites organizadores do protesto, mas sem sucesso. Finalmente, em 25 de janeiro de 2000, a www.etoys.com cedeu todos os direitos à www.etoy.com, após suas ações caírem $70 \%$.

Outros exemplos são o plagiarismo e a invasão de sites restritos para permitir acesso público, como fez o grupo www.0100101110101101.org, que criou sites de net arte, com o apoio do grupo RTmark (www.rtmark.com), para a invasão de games violentos para inserir, dentre outras coisas, imagens de rapazes se beijando. Outro exemplo foi o do "Knowbotic Research" (www.krcf.org), que realizou em Hamburgo o "Connective Force Attack" (Força de Ataque Conectiva), permitindo que a população da cidade, com Cd-roms distribuídos gratuitamente nas estações de metrô, postasse mensagens suas em domínios protegidos por senha, no próprio servidor da prefeitura de Hamburgo.

Essas ações costumam ser consideradas uma das pioneiras daquilo que o CAE denominou "resistência nômade", caracterizada por um tipo de ação múltipla, simultânea, descentralizada e não-localizada, organizada e realizada em rede por 
distintos grupos, no estilo das ações estudadas por Henrique Antoun (2004), ao tratar das novas formas de ativismo político na internet e das "redes de guerra".

Antoun explica como vários dos grupos que formam esses movimentos constroem formas de organização "sem liderança" ("leaderless"), mas formadas por atores e tipos de vínculos que seguem padrões bem estruturados (Antoun, 2004, p. 217). Esses modos de organização contam com uma "arquitetura" ou "topologia" por vezes bastante complexa, de modo a favorecer a intercomunicação entre os vários "nós" que formam a rede. Contudo, Antoun chama a atenção para o fato de que, nessa intercomunicação, mais importante que os modos como se organiza a rede é sua dinâmica, o engajamento e a interação entre seus membros, que faz com que "a comunicação ultrapasse a informação circulante" (Ibid, p. 225).

Contudo, seria um erro achar que o sucesso desse gênero de iniciativa se origine na tecnologia e nas próprias redes virtuais. De fato, como afirma Rousiley Maia, a internet viabilizaria um "ambiente de interconexão", um "complexo de conteúdos" e um "sistema de interações", ao criar "um ambiente de informações denso e plural que ultrapassaria a perspectiva mais unidirecional das mídias massivas" (Maia, 2002, p.46). A autora reconhece, porém, que a internet em si mesma não tem um poder transformador e afirma que há pouca evidência de que o acesso mais amplo às tecnologias irá sozinho expandir o interesse pelas questões políticas. É o problema da participação que sem dúvida não se improvisa ou se força, mas se constrói e que depende muito mais da capacidade educativa e cultural para a utilização dessas ferramentas, como afirma Castells (2002, p. 262). Tal capacidade parece, porém, ser exercitada nesses movimentos que contam cada vez mais com adesão, ainda que pontual e temporária, de pessoas comuns, além de artistas e ativistas.

No trabalho mesmo de mobilização e engajamento produzido por esses grupos, a arte parece ter um papel muito particular: o de criar um campo de forças que levanta e discute de forma crítica, lúdica, irônica e criativa questões socioculturais relevantes através de ações e trabalhos de intervenção urbana ou nas redes virtuais, que passam a servir como fatores de atração e reflexão, primeiro passo para a criação de disposição de adesão e mobilização a causas sociais. 
Nessas ações coletivas, interativas e à distância, são também produzidas novas sociabilidades e paisagens comunicacionais, onde as noções de lugar e presença não são dissolvidas, mas retrabalhadas ao misturar "unipresença física e multipresença mediatizada" (Weissberg in: Parente, 2004, p. 121). Observa-se aí a redefinição das noções de tempo-espaço pela ação em tempo real à distância, pela escrita hipertextual, pela convergência de mídias, pela interatividade e mobilidade. Nestes novos cenários, a comunicação adquire uma feição ubíqua e onipresente, onde deslocamento coincide com os atos de troca e estes independem de uma origem.

Daí a idéia de promover-se uma resistência "nômade", uma prática na qual a comunicação seria "mais lateral que vertical”, como observa Antoun (2004, p. 216) ao tratar da rede como modo de organização social. Antoun observa que nas redes sociais o modo de organização se dá muito mais no tempo que no lugar e que permite, por isso mesmo, uma experiência de descentramento e de cooperativismo muito útil aos novos movimentos ativistas. Articulando global e local, conectando e fazendo emergir narrativas múltiplas em diferentes pontos do planeta, esses movimentos mostram como é possível uma ação eficaz com base em dispositivos móveis e em rede.

No campo das artes, esse gênero de ações têm sido favorecidas com o relativo barateamento de mídias e tecnologias no exterior e no Brasil, que ajuda a disseminar as produções da chamada "arte midiática" ou "tecnológica". Algumas vezes, tais produções vão explorar artisticamente as potencialidades dos novos meios. Outras vezes vão adquirir igualmente um cunho político e ganhar uma dimensão coletiva ao se propagarem na Rede. Exemplos locais seriam grupos como o Vitoriamario, de Curitiba, os paulistas do Bijari e os mineiros do Poro, que usam a internet para gerar campanhas de protesto, mobilizar para ações presenciais, veicular trabalhos de vídeo-arte com cunho político e também intervenções e performances em espaços públicos.

No Brasil, observa-se, contudo, que as novas tecnologias passaram a ser combinados mais com os "antigos" meios para ampliar as possibilidades de intervenção. É quando vemos obras, manifestos e ações organizadas muitas vezes virtualmente atingirem também os espaços cotidianos da cidade, sob a forma de ocupação/resignificação de prédios, ações performáticas nas ruas, além de 
instalações de objetos e obras-processo em espaços públicos, processo conhecido como "intervenções urbanas". Enquanto nos Estados Unidos e na Europa há um maior investimento em alta tecnologia, nas ações dos artistas-ativistas brasileiros evidencia-se a cidade como cenário e também como personagem principal de um processo de criação que se convencionou chamar de "arte pública" (Deutsche, 1996), “arte urbana" (Pallamin, 2000) ou "arte contextual” (Ardenne, 2004).

Porém, já a partir da segunda metade dos anos 90, observa-se a formação, expansão e integração dos movimentos ativistas e artísticos locais nas redes de ativismo mundial, como os movimentos anti-globalização (Seattle) e o Movimento Zapatista, e em redes artísticas como a RAIN - Rijksakademie Artist's Initiative Network e a Res Artis, além dos festivais internacionais de Mídia Tática, Mídia Independente e de Arte Midiática. As "representações brasileiras" desses movimentos e eventos de ativismo eletrônico hoje se disseminam na internet e contam com um número cada vez maior de participantes, que se encontram também presencialmente em várias partes do país.

O processo de colaboração, produção e disseminação em rede, constitui o aspecto propriamente comunicativo e de alteridade das ações de arte e ativismo. Os usos que artistas fazem de tecnologias e mídias para trabalhos que desafiam definições e fronteiras entre arte e política, arte e vida e arte e ciência, coloca a comunicação como elemento central de tais ações.

André Lemos, ao discutir a arte eletrônica no contexto da cibercultura, defende que uma forma de arte que propicia interação e recombinação criativa de informações e processos torna-se ela própria uma "arte de comunicação" (Lemos in: Martins e Machado, 1999, p. 226). Daí tratarmos a performance de artistas e ativistas - que agregam-se sistemática e/ou efemeramente, muitas vezes sem se conhecerem, em torno de objetivos e causas comuns ou não, em lugares próximos ou distantes e que se multiplicam por toda parte - como ações de arte e comunicação. O que estes grupos tentam fazer, a seu modo, é produzir tensões, choques e mudanças através da

\footnotetext{
${ }^{8}$ Modalidade de ação presencial em que artistas e/ou ativistas se apropriam de locais públicos como praças, prédios e ruas para instalação de obras, manifestos ou para realização de performances-protestos. Podem não necessariamente partir da rede, especialmente no Brasil.
} 
arte, de protestos nas redes virtuais ou nos espaços públicos ou da combinação tática de todos esses elementos.

\section{Considerações finais}

Num momento em que o capitalismo se reinventa e passa a operar por meio de uma economia cada vez mais imaterial e em rede, passa a gerar e a promover a circulação de fluxos de toda ordem (capital, informação, bens, serviços, pessoas) em sua lógica de acumulação. Com isso, as formas de poder se "nomadizam" e se tornam cada vez menos geograficamente localizáveis, exigindo que outras formas de resistência - igualmente nômades - sejam criadas.

A aposta que fazemos neste trabalho é a de que relacionar comunicação, arte, tecnologia pode nos oferecer pistas para pensarmos as possibilidades de experimentar novas formas de "resistência" quando a circulação de discursos e práticas sociais são incessantemente reapropriadas e sobrecodificadas pelo capital; quando essa circulação forma híbridos que proliferam no cotidiano sob a forma de produtos culturais que confundem dominação e liberação, controle e escape, comando e resistência, vida e morte, constituindo o que para Peter Pal Pelbart seria o cerne do paradoxo contemporâneo, com relação às formas e relações de poder.

Contudo vale lembrar que, como afirmava Foucault (1988), cada época tende a pensar a si própria como sendo única, o que nos leva frequentemente a vê-la como definitiva e a não perceber possibilidades de mudança. Por isso mesmo ele nos fala do surgimento de uma "nova era de curiosidade", em que se poderia explorar as potencialidades das novas técnicas na direção de uma transformação, afastando-se assim do discurso segundo o qual tudo vai mal e de que vivemos num vazio sem futuro. "Ao contrário", afirma ele, "acredito que há uma pletora. Não estamos sofrendo de um vazio, mas de meios inadequados para pensar sobre tudo o que está acontecendo" (Foucault, 1988, p.327).

Portanto, cabe perguntar que configurações poderiam assumir práticas e discursos críticos num momento em que oposições e totalidades parecem perder sentido e em que as formas de poder se nomadizam e passam a operar não mais apenas em lugares, mas nos interstícios do corpo e da subjetividade. Isso nos permitiria pensar tanto nos graus de mediatização da vida social e suas implicações 
para nossas visões de mundo, quanto nas capacidades criativas, como parece ocorrer nas ações desse "novo ativismo artístico”, que procuramos aqui brevemente esboçar.

Ao levantarmos estas questões, estamos nos aliando ao pensamento de Pelbart, quando ele afirma, certamente inspirado em Guattari, que somos levados hoje a consumir não apenas bens, mas, sobretudo, formas e sentidos de vida, que absorvemos todos os dias ao acessar imagens, informações, serviços etc. Esse "consumo" corresponderia a uma "captura do desejo" e a uma "colonização do inconsciente", que faz do capital uma "megamáquina de produção de subjetividade". (Pelbart, 2004, p. 20)

A partir dessa constatação, Pelbart se pergunta como seria possível fazer surgir no interior dessa mesma máquina processos que descolem desse tipo de funcionamento, como criar novos espaços subjetivos "na contramão da serialização e das reterritorializações propostas a cada minuto pela economia material e imaterial" (2003, p. 22). Pelbart crê que, em meio à complexificação de nossas sociedades e dos modos de vida, ante o acúmulo do conhecimento e da informação, será sempre possível imaginar também o surgimento de uma heterogeneidade, uma polifonia capaz de gerar contrapontos, dissonâncias e fissuras. Trata-se então de produzir novas estratégias para a produção de diferença, pois é sempre possível pensar formas de resistência a partir das próprias instâncias em que se articulam os mecanismos de controle.

Assim, é sempre possível inventar novos modos de vida, novas sensibilidades e desejos a partir de operações diferenciadas com os elementos heterogêneos presentes na comunicação, na cidade, na arte e nas tecnologias, que formam uma série de conexões que constituem aquilo que Deleuze e Guattari (1977, p. 124) chamaram de "agenciamentos coletivos de enunciação". Os agenciamentos seriam modos de arranjo de sentido que se organizam segundo determinados pressupostos. São eles que denotam o caráter essencialmente social da produção de discursos e das práticas vividas em escala individual ou coletiva - que nos atravessam e constituem sem que muitas vezes venhamos a nos dar conta.

Deleuze e Guattari acreditam que os agenciamentos não são sempre estáveis. Antes, apresentariam "pontas de desterritorialização", ou seja, possibilidades de desestabilização. São essas "pontas” que vão permitir o surgimento daquilo que estes 
autores chamaram de "linhas de fuga", espécie de elementos de "escape" que, contudo, não desejam escapar do mundo e seus embates, mas, ao contrário, produzir novas lutas a cada instante e em novos lugares, onde antes nada se via. Em suas palavras: "fazer fugir, fazer algo escapar, fazer um sistema vazar" (Deleuze e Parnet, 1998:49).

As ações de arte e ativismo que apresentamos parecem ser um exemplo dessas estratégias. No entanto, mais do que soluções, elas nos remetem a perguntas ainda sem resposta e que nos convidam a investigar esse gênero de fenômeno. Tentar compreender o midiático, o tecnológico, o artístico e o urbano, e os tipos de práticas e discursos que estas instâncias produzem hoje, problematizando-as, constitui uma tarefa mais que necessária: a de por em questão as lógicas das práticas culturais e comunicativas na atualidade e discutir as dimensões das novas experiências sociais que elas podem engendrar.

\section{Referências bibliográficas}

ANTOUN, H. Democracia, Multidão e Guerra no Ciberespaço. In: André Parente. (Org.). Tramas da Rede: Novas dimensões filosóficas, estéticas e políticas da comunicação. 1 ed. Porto Alegre, 2004.

ARDENNE, Paul. Un art contextuel. Paris: Éditions Flammarion, 2004.

BERGER, René. Tornar-se sobrevivente do futuro? In: Domingues, Diana (Org.) Arte e Vida no século XXI. São Paulo: Unesp, 2003.

CRITICAL ART ENSEMBLE. Electronic Civil Desobidience and other unpopular ideas. Nova York: Autonomedia, 1996.

Autonomedia, 1994.

. The Electronic Disturbance. Nova York:

DE CERTEAU, Michel. A invenção do cotidiano. Petrópolis: Vozes, 1994. 
DELEUZE, G. Conversações. Rio de Janeiro: Ed. 34, 1992.

DELEUZE, Gilles e GUATTARI, F. Mille Plateaux. Paris: Éditions du Minuit, 1980.

DELEUZE, Gilles e PARNET, C. Diálogos. São Paulo: Escuta, 1998.

DEUTSCHE, Rosalyn. Evictions. Art and Spacial Politics. Cambridge. Mass. MIT Press, 1996.

FOUCAULT, M. Politics, Philosophy, Culture. Londres/Nova York: Routledge, 1988.

GOHN, Maria da Glória. Movimentos sociais no início do século XXI. Petrópolis: Vozes, 2003.

GONÇALVES, Fernando. Fabulações eletrônicas: poéticas da comunicação e da tecnologia em Laurie Anderson. Rio de Janeiro: E-papers, 2006.

LEMOS, André. Cibercidades (Online). Disponível em: http://www.facom.ufba.br/ciberpesquisa/txt and1.htm. Acesso em 20/o3/o6.

LOVNIK, Geert e GARCIA, David. O ABC da mídia tática. In: Rizoma.Net, 2003. Disponível online: http://www.rizoma.net/desenv/interna.php?id=131\&secao=intervencao. Acesso em 23/03/2005.

LOVNIK, Geert. Tecnopolítica em ação. In: Tropico, 2005. Disponível: http://p.php.uol.com.br/tropico/html/textos/2668,1.shl. Acesso em 02/02/2006.

MAIA, Rousiley. Redes cívicas e Internet: do ambiente informativo denso às condições da deliberação pública. In: EISENBERG, José e CEPIK, Marco (Org.). Internet e política: teoria e prática da democracia eletrônica. Belo Horizonte: Ed. UFMG, 2002.

PALLAMIN, Vera M. Arte Urbana. São Paulo: Annablume, 1998.

PELBART, Peter Pál. Vida capital: ensaios de biopolítica. São Paulo: Iluminuras, 2003.

ROSAS, Ricardo e WELLS, Tatiana. Que venha a mídia tática. In: Rizoma.net, 2003. Disponível online:

http://www.rizoma.net/interna.php?id=174\&secao=intervencao. Acesso em 12/08/2005.

ROSAS, Ricardo. Nome: coletivos, Senha: colaboração. In: Rizoma.net, 2003. Disponível em: http://www.rizoma.net/desenv/interna.php?id=170\&secao=intervencao. Acesso em 21/01/o6.

SCHERER-WARREN, Ilse. Redes de movimentos sociais. São Paulo: Loyola, 1993.

TRIBE, Mark e JANA, Reena. Arte y Nuevas Tecnologías. Köln: Taschen, 2006.

WEISSBERG, Jean-Louis. Paradoxos da Teleinformática. In: PARENTE, André. (Org.). Tramas da Rede: novas dimensões filosóficas, estéticas e políticas da comunicação. 1 ed. Porto Alegre, 2004. 